\title{
Mastectomia como prevenção para o câncer de mama
}

\author{
Mastectomy as a prevention for breast cancer \\ Mastectomía como prevención del cáncer de mama
}

Recebido: 10/01/2021 | Revisado: 11/01/2021 | Aceito: 11/01/2021 | Publicado: 11/01/2021

Walber Barbosa de Andrade

ORCID: https://orcid.org/0000-0003-0290-5009

Centro Universitário UniAges, Brasil

E-mail: blekwalber@hotmail.com

Maria de Fátima Santana de Souza Guerra

ORCID: https://orcid.org/0000-0002-2760-8230

Centro Universitário UniAges, Brasil

E-mail: marinaide10@gmail.com

Ana Mara Borges Araujo

ORCID: https://orcid.org/0000-0003-4065-241X

Centro Universitário UniAges, Brasil

E-mail: anamaraborges_@hotmail.com

Jaciara Pinheiro de Souza

ORCID: https://orcid.org/0000-0002-4056-974X

Centro Universitário UniAges, Brasil

E-mail: jacipinheirosouza@hotmail.com

Murilo de Jesus Porto

ORCID: https://orcid.org/0000-0003-2339-8173

Universidade do Estado da Bahia, Brasil

E-mail: murilo.porto@hotmail.com

Maciel Borges Nascimento

ORCID: https://orcid.org/0000-0002-9190-6072 Centro Universitário UniAges, Brasil E-mail: macielborges17@gmail.com

Welde Natan Borges de Santana

ORCID: https://orcid.org/0000-0001-9781-2934 Centro Universitário UniAges, Brasil

E-mail:welder_natan@ hotmail.com

Gilvania Piedade Santos

ORCID: https://orcid.org/0000-0003-2435-0198 Centro Universitário UniAges, Brasil E-mail: gilvania.piedade@gmail.com

Antero Fontes de Santana

ORCID: https://orcid.org/0000-0002-8944-3216 Centro Universitário UniAges, Brasil E-mail: anterosantana@hotmail.com

Sandra Regina Santana Silva

ORCID: https://orcid.org/0000-0002-8218-3407 Centro Universitário UniAges, Brasil

E-mail: sandrareginaenfa@hotmail.com

\begin{abstract}
Resumo
A descoberta da possibilidade de se prevê o desenvolvimento do câncer de mama tornou-se possível, assim uma mulher pode realizar um exame genético e descobrir qual a sua probabilidade de desenvolver um câncer de mama, no entanto, a descoberta da probabilidade não quer dizer que a mastectomia é indicada. Neste tocante o trabalho tem como objetivo esclarecer informações sobre o uso da mastectomia como prevenção para o câncer de mama. Trata-se de uma pesquisa de caráter narrativo descritiva com abordagem qualitativa, de análise literária através dos bancos de dados: bibliotecas virtuais (SciELO - Scientifi c Electronic Library Online (http//www.scielo.org/ index.php); LILACS (Literatura Latino-Americana e do Caribe em Ciências da Saúde); BVS - Biblioteca Virtual em Saúde (http//www.base. bvs.br/index.php); livros de referência; sites confiáveis. Não houve restrição de ano para as publicações selecionadas que envolviam a temática estudada. Mediante levantamento bibliográfico, conclui-se que a mastectomia profilática é uma boa opção para o combate ao câncer de mama, porém não pode ser aplicada como uma receita que cabe a todos, restringindo-se, no geral, aos casos que haja mutação nos genes supressores de tumor BRCA1, BRCA2 e que se tenha histórico familiar de câncer de mama. Vale ressaltar, que o rastreamento genético ainda não é algo acessível a grande massa da população. É concreto que a experiência da mastectomia varia de acordo com cada mulher, envolvendo, no geral, sentimentos de medo, angústia e baixa autoestima, pois remete a retirada do símbolo da feminilidade, a mama.
\end{abstract}


Palavras-chave: Câncer de mama; Mastectómia; Fatores positivos; Fatores negativos.

\begin{abstract}
The discovery of the possibility of predicting the development of breast cancer has possible, so a woman can perform a genetic test and fi nd out what her probability of developing breast cancer, however, the discovery of the probability does not mean mastectomy is indicated. In this regard, the work aims to clarify what breast cancer is, how it develops, which genes are involved in the neoplastic process and what forms of prevention, as well as explaining what is mastectomy and what are its types, addressing the positives and negatives for the lives of patients who undergo such surgery. It is a descriptive narrative research with a qualitative approach, of literary analysis through the databases: virtual libraries (SciELO - Scientifi c Electronic Library Online (http // www.scielo.org / index.php); LILACS (Latin American and Caribbean Literature in Health Sciences); VHL - Virtual Health Library (http // www.base. Bvs.br/index.php); reference books; reliable websites. There was no year restriction for selected publications that involved the studied topic.Conclusion: Like other breast cancer prevention methods, mastectomy is a measure that has its positive and negative points, but in short it is an effective preventive measure, but more studies are needed to solidify the practices of this method as prevention.
\end{abstract}

Keywords: Breast cancer; Mastectomy; Positive factors; Negative factors.

\title{
Resume
}

El descubrimiento de la posibilidad de predecir el desarrollo de cáncer de mama se ha hecho posible, por lo que una mujer puede realizar una prueba genética y averiguar cuál es su probabilidad de desarrollar cáncer de mama, sin embargo, el descubrimiento de la probabilidad no significa que está indicada la mastectomía. En este sentido, el trabajo tiene como objetivo aclarar información sobre el uso de la mastectomía como prevención del cáncer de mama. Se trata de una investigación narrativa descriptiva con enfoque cualitativo, de análisis literario a través de las bases de datos: bibliotecas virtuales (SciELO - Scientific Electronic Library Online (http // www.scielo.org / index.php); LILACS ( Literatura Latinoamericana y del Caribe en Ciencias de la Salud); BVS - Biblioteca Virtual en Salud (http // www.base. Bvs.br/index.php); libros de referencia; sitios web confiables. No hubo restricción de año para Publicaciones seleccionadas que involucraron la temática estudiada. A partir de un relevamiento bibliográfico se concluye que la mastectomía profiláctica es una buena opción para combatir el cáncer de mama, sin embargo no se puede aplicar como una receta que se ajuste a todos, siendo restringida, en general, cuando hay una mutación en los genes supresores de tumores BRCA1, BRCA2 y antecedentes familiares de cáncer de mama. Cabe mencionar que el cribado genético aún no es accesible a una gran masa de la población. Es concreto que la experiencia de la mastectomíavaría según cada mujer, involucrando, en general, sentimientos de miedo, angustia y baja autoestima, ya que se refiere a la remoción del símbolo de la feminidad, el pecho.

Palabras clave: Cáncer de mama; Mastectomía; Factores positivos; Factores negativos.

\section{Introdução}

Em decorrência do elevado nível de incidência, morbimortalidade e elevado custo para o tratamento, Melo et al in Viana, Leão e Figueiredo (2010), demonstram que o câncer de mama tornou-se um grave problema de saúde pública, não apenas no Brasil, mas em todo o mundo, mesmo sendo uma neoplasia milenar, mexe muito com o imaginário feminino, de modo que lidar com alterações corporais é algo extremamente delicado e difícil.

Segundo Vieira, Lopes e Shimo (2007), em geral, essa neoplasia é uma doença considerada destruidora, sendo sentida, por vezes, como um castigo, uma punição divina, sentimentos difíceis de serem administrados, principalmente, no que concerne ao estigma social da morte, originando reações preconceituosas. O medo não compete apenas ao prognóstico da doença, o qual geralmente é bom, mas envolve sempre os sentimentos de rejeição. O medo da rejeição soma-se ao da mutilação que é algo muito intenso, ocorrem mudanças na autoimagem feminina, e consequentemente em sua identidade, já que as mamas seriam a representatividade da feminilidade (Duarte, Andrade 2003, in Vieira, Lopes \& Shimo, 2007).

Na maioria das vezes, o diagnóstico de câncer de mama desperta reações diferentes em cada mulher. "Ao entrar em ação de enfrentamento, cada portador de uma mesma enfermidade pode se expressar de maneiras diferentes: física, emocional e espiritual" (Figueiredo et al, 2010, p3). Porém, vale ressaltar que apesar de serem distintas, essas reações são, no geral, carregadas de pensamentos negativos segundo Vieira, Lopes e Shimo (2007).

O tratamento do câncer pode ser realizado através da mastectomia, sendo o mais utilizado nessa patologia, e consiste em uma série de alterações vivenciadas pelas pacientes, pois surge como um processo cirúrgico agressivo, acompanhado de 
resultados traumático para a vida e bem-estar da mulher, justamente por ser um conhecimento emocionalmente complicado, necessitando de uma preparação adequada (Nacep, 2012 \& Machado, Soares, Oliveira, 2017).

Compreender as representações sociais que a doença tem para as pacientes acometidas é algo essencial para que os profissionais de enfermagem possam desenvolver suas competências e habilidades, de modo, a educar paciente e família à nova realidade. Cientes de que a neoplasia mamária precisa ser, de acordo com Vieira, Lopes e Shimo (2007), pensada em toda sua amplitude biopsicossocial, torna-se indispensável conhecer efetivamente o paciente a quem a assistência será prestada, para que essa se desenvolva de forma efetiva e satisfatória.

Por tempos, as mulheres vêm sofrendo com a manifestação do câncer de mama, ficando fragilizadas e receosas, já que receber o diagnóstico de tal doença desperta no indivíduo o medo de ter a sua vitalidade sugada, até o próprio tratamento carrega consigo o sentimento de impotência e de vulnerabilidade, além de todos os estigmas sociais que o envolve. Dessa maneira, justifica-se o desenvolvimento do presente trabalho, este que tem como objetivo esclarecer informações sobre o uso da mastectomia como prevenção para o câncer de mama.

\section{Metodologia}

Trata-se de um estudo no caráter narrativo descritiva com abordagem qualitativa, de análise literária através dos bancos de dados: bibliotecas virtuais SciELO - Scientifi c Electronic Library Online (http//www.scielo.org/ index.php); LILACS (Literatura Latino-Americana e do Caribe em Ciências da Saúde); BVS - Biblioteca Virtual em Saúde (http//www.base. bvs.br/index.php); livros de referência; sites confiáveis. Não houve restrição de ano para as publicações selecionadas que envolviam a temática estudada.

A pesquisa bibliográfica é de extrema relevância pois busca explicar um problema a partir de conhecimentos já disponibilizados em obras literárias publicadas. Esse tipo de pesquisa disponibiliza ao pesquisador um leque de conhecimento e teorias disponíveis na área estudada, buscando explicar o fenômeno através da investigação dos textos existentes (KOCHE, 1999).

No levantamento bibliográfico, foram selecionados trabalhos que contemplasse a temática em estudo, realizando-se, inicialmente, uma leitura prévia dos títulos; resumos; por último a leitura do texto completo das publicações previamente selecionadas. Além disso, para esta revisão narrativa, foram utilizadas também as etapas de verificação da questão temática, estabelecimento dos critérios para a seleção da amostra, análise e interpretação dos resultados e apresentação da revisão.

Utilizou-se como critérios de exclusão trabalhos desconexos ou que fugissem do tema estudado, editoriais e relatos de casos. E como critérios de inclusão os textos que abordavam o público de estudo (feminino) e o tema câncer de mama, não havendo restrição de ano de publicação.

\section{Resultados e Discussão}

\section{Câncer de Mama}

O câncer de mama é definido, de acordo com Machado et al in Viana, Leão e Figueiredo (2010), como uma doença degenerativa que atinge a mulher independente de classe social e cultura, porém essas duas variáveis são influentes na aceitação e forma que a paciente encara o diagnóstico da doença.

Em geral, mulheres que apresentam a doença aos 25 anos, é relativamente raro, já que de acordo com D’Ávila et al (2000), menos de $1 \%$ de todo câncer de mama ocorrem em mulheres com idade até 25 anos e as chances aumentam se a paciente apresentar história familiar de neoplasia. 
A princípio deve ser entendido que o câncer de mama é uma neoplasia. Para Robbins e Cotran (2010) a palavra neoplasia significa novo crescimento, geralmente acompanhada de um tumor, ou seja, de um edema oriundo do processo inflamatório, envolvido no tecido. Segundo Robbins e Cotran (2010, p260) “O neoplasma é uma massa anormal de tecido, cujo crescimento é excessivo e não coordenado com aqueles dos tecidos normais, e persiste da mesma maneira excessiva após a interrupção do estímulo que originou as alterações.” Assim uma neoplasia é caracterizada pelo aumento de células, de forma desordenada, dentro de um tecido.

Dentro desta ótica existem dois conceitos: o de tumor benigno e de neoplasia maligna. Segundo Robbins e Cotran (2010, p. 260) “O tumor é benigno quando suas características micro e macroscópicas são consideradas relativamente inocentes, significando que ele permanece localizado, não consegue se disseminar para outros sítios e geralmente pode ser removido por cirurgia local". Enquanto que a neoplasia maligna, seja na mama ou em outro tecido, também é conhecida como câncer, é mais invasiva tendo potencial para emergir outros tecidos, tornando mais crítico o quadro clínico do paciente. Segundo Robbins e Cotran (2010, p. 260):

Os tumores malignos são referidos coletivamente como cânceres, um derivado da palavra latina caranguejo, pois se aderem a qualquer região em que estejam, de maneira obstinada, similar a um caranguejo. $\mathrm{O}$ termo maligno, quando aplicado a um neoplasma, significa que a lesão pode invadir e destruir as estruturas adjacentes e se disseminar para os sítios distantes (metastatizar) levando à morte.

Com o avanço da tecnologia e principalmente da genética, foi possível identificar pontos específicos no DNA e identificar falhas no mesmo. Segundo Silver (2001, p. 38) “O espantoso é que o DNA presente num ser humano consciente é o mesmo DNA presente numa ameba minúscula. A razão pela qual esses dois organismos parecem diferentes entre si é as mensagens que elas levam em suas respectivas moléculas de DNA.” Desta forma o homem passou a ter uma nova visão sobre os elementos que envolvem o câncer de mama podendo identificar os principais genes que são responsáveis pela manifestação da doença. Segundo Monteiro et al. (2011, p.444):

Com a identificação dos genes de suscetibilidade do câncer de mama BRCA1 e BRCA2 surgiu entre as mulheres com risco (decorrente de histórico familiar da doença) de serem portadoras dessa mutação, um largo interesse em fazer um mapeamento genético. Mulheres com a mutação nesses genes têm um risco cumulativo (50\% a $85 \%)$ ao longo da vida de ter uma neoplasia mamária invasiva, principalmente a partir dos 70 anos de idade. Nessas mulheres, o risco de se desenvolver câncer de mama começa aos 25 anos e a chance de sobreviver à doença é de $50 \%$ em 10 anos (mesmo risco das mulheres sem a mutação).

O conhecimento no campo genético é uma grande ferramenta para melhor lidar com as doenças que se fazem presente. Na obra "De volta ao Éden” de Silver (2001), é possível perceber os inúmeros avanços neste campo, os quais proporcionam o conhecimento da suscetibilidade que uma pessoa possui para determinada doença, inclusive para o câncer, através de uma análise do DNA, o que proporciona subsídios para realizar ações que reduzam o risco da doença e propicia o acompanhamento adequado para diagnosticá-la mais rápido possível o que contribui para melhores prognósticos.

\section{Genes Envolvidos no Câncer de Mama}

A todo momento, o ser humano está em processo de divisão celular, envolvendo diversas moléculas que contribuem para que não aja alterações no genoma. Por vezes, devido à estimulação de elementos físicos, químicos ou biológicos, ocorre falha na cadeia do DNA desencadeando mutação e o organismo não consegue reparar. O problema aumenta quando estas mutações envolvem genes que desempenham funções importantes no processo de divisão celular, um destes casos é a mutação dos proto-oncogênes, entre eles o c-erbB-2 (HER2) que regula o processo de multiplicação celular. Quando este gene sofre 
mutação, a célula fica em constante processo de multiplicação sem saber a hora de parar de se replicar, assim passam a ser denominados de oncogênese, principal responsável pelo processo neoplásico (Amendola \& Vieira, 2005).

Dentre os genes que estão envolvidos no processo de proteção do genoma, o P53 e os genes BRCA1 e BRCA2, são os que possuem funções extremamente relevantes, estes genes são responsáveis por frear o processo de replicação celular, reduzindo a replicação ou induzindo a morte celular programada (apoptose), principalmente, de células que apresentam danos em sua estrutura, protegendo-as de um crescimento desordenado, sendo assim denominados de genes supressores de tumor. Segundo Amendola e Vieira (2005, p. 327):

As estimativas iniciais para o risco de desenvolvimento de câncer de mama ao longo da vida - penetrância - em mulheres portadoras de mutações no gene BRCA1, eram superiores a 85\%. Estudos mais recentes, no entanto, sugerem um risco de 50 a $80 \%$ para o desenvolvimento de câncer de mama até os 70 anos. O risco para portadores de mutação em BRCA2, se aproxima daquele estimado para BRCA1, embora o acometimento, em idade mais avançada, seja relatado para BRCA2.

Desta forma fica entendido que mulheres portadoras de mutação nos genes BRCA1 e BRCA2, e com histórico familiar de câncer de mama, têm grandes probabilidades de desenvolver a doença, e quanto antes for descoberto estas alterações, através do mapeamento genético, torna-se mais eficaz os métodos de prevenção, com isso algumas mulheres passaram a ver a mastectomia bilateral como uma medida profilática à doença.

\section{Prevenção e Rastreamento do Câncer de Mama}

As formas mais adequadas e eficazes para realizar detecção precoce da doença são: o autoexame das mamas; exame clínico; mamografia. A mamografia, assim com a ultrassonografia, de acordo com Machado et al in Viana, Leão e Figueiredo (2010), são exames capazes de detectar tumores não palpáveis, representam altos custos e não promovem resultados operacionais para que estejam disponíveis a grande massa da população. O autoexame é escolhido como a estratégia para prevenção secundária, fato que nos leva a perceber que parte da população fica em desvantagem, ao tempo que, segundo Freitas et al in Viana, Leão e Figueiredo (2010), menos de 50\% das mulheres realizam o autoexame periodicamente.

De acordo como Brasil (2013) deve ser observado alguns critérios para fazer o rastreamento do câncer de mama, sendo indicado que: mulheres de 40 a 49 anos realizem exame clínico das mamas anualmente e, se for detectado alterações, a paciente dever realizar mamografia; mulheres de 50 a 69 anos deve fazer exame clínico das mamas anualmente e, se for detectado alterações, a paciente dever realizar mamografia a cada dois anos; mulheres de 35 anos ou mais com risco elevado deverão passar por exame clínico das mamas anualmente e se for detectado alterações a paciente deve realizar mamografia anual.

São fatores de risco a desenvolver câncer de mama: ter menarca precoce (menor que 12 anos); ter menopausa tardia (maior que 50 anos); ter a primeira gravidez após 30 anos; nuliparidade; obesidade; ingesta regular de álcool; sedentarismo; histórico familiar, caso de câncer com menos de 50 anos (Brasil, 2013).

São fatores de risco muito elevado a desenvolver câncer de mama: ter parentes de primeiro grau com câncer antes dos 50 anos; ter parente de primeiro grau com câncer bilateral em qualquer idade; ter algum caso de câncer de mama masculino na família (Brasil, 2013).

Observar todos os fatores de risco e realizar os exames de rastreamento do câncer de mama são imprescindíveis para fazer o diagnóstico o mais precocemente, assim evitando complicações maiores em decorrência da doença. Vale ressaltar que com o avanço da tecnologia e da engenharia genética já é possível realizar o mapeamento genético para descobrir se um determinado indivíduo está ou não mais suscetível a desenvolver o câncer de mama, abrindo caminhos para a paciente realizar 
uma mastectomia profilática, a fim de se evitar o surgimento da doença, porém tal exame ainda tem um custo elevado e são poucas pessoas que tem acesso a eles (Monteiro et al, 2011).

Na obra "Como e porque as desigualdades sociais fazem mal à saúde" escrita por Barata (2009), percebe-se que mesmo as desigualdades sociais não determinando o aparecimento do câncer, ela representa influência significativa em sua detecção, tratamento e consequente prognóstico, assim a autora afirma que se devem criar políticas de saúde equânimes que promovam igualdade nas oportunidades de saúde.

É indispensável que os profissionais de enfermagem conheçam os aspectos fisiopatológicos que envolvem o câncer, por meio do qual, afirmam Machado et al in Viana, Leão e Figueiredo (2010), estará ciente das alterações que esta causa no corpo, possibilitando direcionar o olhar com maior especificidade, para que possam atender as fragilidades que decorrem do adoecimento.

Tão logo que ocorre o diagnóstico da doença, a paciente sofre grande impacto relacionado ao estigma social, sentindose, por vezes, que as neoplasias são mortais, mutilantes e incapacitantes; fatores que os autores supramencionados afirmam causar alterações emocionais, psicológicas, da autoimagem e autoestima. Os autores reiteram que tais aspectos merecem abordagem de igual importância como os problemas de cunho biológico, como reações provenientes as formas de tratamento e feridas operatórias “[...] Compreendê-lo dessa forma é cuidar dele como corpo-sujeito" (Silva et al; Viana, Leão \& Figueiredo, 2010).

Gomes, Skaba e Vieira (2002) relatam que todo o medo que circunda o câncer advém desse contato próximo que a doença estabelece com a morte, isso porque o ser humano não está acostumado a tomar contato com sua finitude, buscando meios de fuga, por vezes, expresso na não aceitação do diagnóstico. Na obra “Corpos de passagem” de Sant'Anna (2001), deparamo-nos com tal realidade, onde percebe-se uma necessidade insana de frear o curso natural das coisas, “[...] Há corpos que recusam ser passagem" (Sant'anna, 2001, p.106). As mamas é o órgão mais relacionado a feminilidade, sensualidade, de modo que, adquirir uma doença em tal órgão, destrói todas as possibilidades de simbolização da mulher enquanto ser feminino (Gomes, Skaba \& Vieira, 2002).

Diante de todas as representações que o câncer de mama apresenta, torna-se fácil perceber que as mulheres necessitam inegavelmente de grande apoio, haja visto que as alterações causadas pela doença, colocam-na em situação de passividade. Os autores supracitados, demonstram que deve-se tecer uma rede de apoio social à mulher, para que o enfrentamento de todas as etapas torne-se menos pesado, impedindo-a de desistir (Gomes, Skaba \& Vieira, 2002). Compete à família, aos amigos e aos profissionais envolvidos no cuidado, fortalecerem a paciente para a luta a ser travada contra a doença, deixando-a ciente que, mesmo ocorrendo algumas mudanças as quais devem adaptar-se, já existem tratamentos eficazes e que a qualidade de vida pode sim ser mantida.

Em suma, como o mapeamento genético não é um exame muito acessível, grande parte da população mundial não tem acesso a este método de investigação, tornando a assistência desigual que Segundo Barata (2009, p. 20) “As desigualdades sociais em saúde podem manifestar-se de maneira diversa no que diz respeito ao processo saúde-doença em si, bem como ao acesso e utilização de serviços de saúde. As desigualdades no estado de saúde estão de modo geral fortemente atreladas à organização social e tendem a refletir o grau de iniquidade existente em cada sociedade.” Desta forma as possibilidades de prevenção do câncer de mama se tornam desiguais, mas as autoridades públicas devem buscar sanar desigualdades na assistência durante a luta contra o câncer de mama, garantindo a paciente a melhor estratégia de combate à doença. 


\section{Mastectomia Como Prevenção}

A mastectomia é o procedimento cirúrgico de retirada das mamas, podendo ser subclassificação em: mastectomia radical parcial; mastectomia radical modificada; mastectomia total ou simples; mastectomia radical. Na mastectomia radical parcial, o cirurgião remove o câncer com um pouco do tecido normal ao redor e, em geral, alguns dos linfonodos das axilas. Em uma mastectomia radical modificada, o cirurgião remove a mama, a parte acima dos músculos peitorais e alguns dos linfonodos axilares. Em uma mastectomia total (ou simples), o cirurgião remove a mama inteira. Enquanto que na mastectomia radical, o cirurgião remove a mama, músculos peitorais e a maioria dos linfonodos axilares inferiores, médios e superiores (Monteiro et al, 2011).

Certos estudos atualizados apontam uma presciência de 27 milhões de casos novos de câncer para o ano de 2030 em todo território mundial, e com 17 milhões de casos com óbitos patológicos. Esta estimativa ocorrerá em alguns países, dentre eles o Brasil (Inca, 2012).

A mastectomia seria uma medida de prevenção para o câncer de mama, porém a grandes controvérsias a respeito dos aspectos psicossociais que a envolve. Segundo Monteiro et al (2011, p444):

A mastectomia possui um caráter agressivo, mutilante e traumatizante para a vida e saúde da mulher, já que prejudica sua dimensão bio-psicossocio-espiritual. Ademais, proporciona alterações em sua imagem corporal, identidade e autoestima, podendo repercutir na expressão de sua sexualidade e também despertar sintomas de depressão e ansiedade.

Além destas problemáticas, as mulheres mastectomizadas perdem o poder de nutrirem os filhos com o seu próprio leite, acarretando impactos emocionais para o binômio: mãe e filho. Para Silva et al (2010, p731):

As mamas, assumem então, um duplo significado para a mulher, desde a expressão de sua feminilidade até a essencial tarefa da amamentação. A mama tem importância como nutriz, além de acrescentar um importante complemento à imagem corporal e identidade feminina. Percebe-se que as mulheres entrevistadas representam a mama como símbolo da feminilidade, estética, sensualidade, bem como da maternidade. As mamas, além de desempenharem um importante papel fisiológico em todas as fases do desenvolvimento feminino que vão desde a puberdade à idade adulta, também representam em nossa cultura um símbolo de identificação da mulher e sua feminilidade expressas pelo erotismo, pela sensualidade, pela sexualidade e pela maternidade. Logo, as mamas ganham uma dimensão que simboliza, além da sexualidade, a importante função da maternidade.

Vale ressaltar, que um dos problemas percebidos da mastectomia profilática é a forma que ela é transmitida pela mídia à população. A utilização do método em uma atriz muito famosa (Angelina Jolie), de certa forma, influenciou e influencia a população a seguir o exemplo. Para Silva (2010, p. 93) "A competitividade das instituições do setor de saúde através de propaganda e ação autoritária faz com que as pessoas se confundam". A mastectomia profilática não é indicada em todos os casos, o que deve ser levado em conta é o tipo de mutação que ela possui e diversos outros fatores como histórico familiar. No geral, ela é mais indicada em casos de mutação nos genes BRCA1, BRCA2 e com histórico de câncer de mama na família, situação em que a mastectomia irá reduzir drasticamente as chances de se ter um câncer de mama.

\section{O Enfermeiro No Cuidado À Saúde Da Mulher}

Cabe ao profissional de enfermagem contribuir para que as representações do câncer de mama sejam reformuladas. A intervenção e atuação da enfermagem frente ao câncer de mama enfrentam desafios referentes aos aspectos anteriormente discutidos. A fim de satisfatoriamente alcançar metas, Machado et al in Viana, Leão e Figueiredo (2010), relatam que a atuação de Enfermagem deve ser implementada de maneira organizada, sistematizando a assistência, sendo a SAE 
(sistematização da assistência de Enfermagem), a ferramenta adequada. Objetiva-se reduzir agravos, medo, ansiedade e prover melhor qualidade de vida, propondo meios para que ela consiga adaptar-se à sua imagem, reestruturando sua autoestima.

O cuidado de enfermagem se desenvolve no sentido de promover e restaurar o bem-estar físico, psíquico e social ampliando as possibilidades de o cliente viver e prosperar. Nessa perspectiva o cuidado de enfermagem se apresenta na pratica assistencial como um conjunto que transcende o tempo de ação, exigindo do profissional de enfermagem uma visão caleidoscópica sobre o corpo que está sendo cuidado. (Machado et al \& Viana, Leão, Figueiredo, 2010).

Assim, os mesmos autores defendem que a fim de atender aos princípios do cuidado holístico, este deve ser desenvolvido a partir de duas bases dimensionais, uma objetiva, que compete à execução de procedimentos técnicos, e a outra subjetiva, encarregada de toda sensibilidade, criatividade e intuição para cuidar do outro ser. É, portanto, indispensável que as duas bases de cuidado andem de mãos dadas.

O valor do cuidado de enfermagem, incide na adoção de uma concepção ética que contemple a vida como um bem valioso, requerendo a adoção de posturas humanísticas frente aos sofrimentos físicos, espiritual e psíquico do cliente. (Machado et al \& Viana, Leão, Figueiredo, 2010).

O cuidado humanizado estabelece-se a partir da comunicação através da capacidade de ouvir as dúvidas e angústias da paciente e da sua família. É uma forma de mostrar-se presente, disponível, solidário, atitude muito valorizada pelos que sofrem direta ou indiretamente os efeitos da presença desta neoplasia mamária (Silva et al in Viana, Leão \& Figueiredo, 2010).

A mulher ao receber o diagnóstico de câncer de mama é visto como uma ameaça para ela e familiares. A decisão familiar é alterada por causa da doença e diversos temores surgem. O maior medo dessas mulheres é em relação a sobrevivência, por seguinte, surge a inquietação com o tratamento. Há também a preocupação com a mutilação, desfiguração e as consequências em relação a vida sexual (Gimenes; Queiroz, 1997 apud Duarte \& Andrade, 2003).

Tecer vínculos com o paciente e família é crucial para que se estabeleça uma relação de confiança, assunto amplamente discutido na obra "A parteira de Monte Azul”, a qual demonstra que, a partir da criação de vínculos e tratando os problemas da paciente de maneira humanizada e respeitosa, é possível impulsioná-la a seguir corretamente as instruções do profissional de saúde, garantindo melhor receptividade e efetividade das ações preventivas e curativas (Silva, 2010).

Análises realizadas com pessoas que possuem câncer de mama relatam que o diagnóstico, terapêutica e suas sequelas são muito estressantes para essas mulheres (Gimenes, 1997, Carver, 1993, Gandini, 1995 apud Duarte \& Andrade, 2003).

A amputação da mama sobrecarrega um significado traumático para a mulher, afetando a sua identidade, além das prováveis consequências físicas e psicológicas após a cirurgia. Na maioria das vezes, elas sentem-se com baixa autoestima, sentimento de inferioridade e medo de rejeição do parceiro (Silva, 2008 apud Prates, Zanini \& Veloso, 2012).

\section{Considerações Finais}

Conclui-se que a mastectomia profilática é uma boa opção para o combate ao câncer de mama, porém não pode ser aplicada como uma receita que cabe a todos, restringindo-se, no geral, aos casos que haja mutação nos genes supressores de tumor BRCA1, BRCA2 e que se tenha histórico familiar de câncer de mama. Vale ressaltar, que o rastreamento genético ainda não é algo acessível a grande massa da população.

É concreto que a experiência da mastectomia varia de acordo com cada mulher, envolvendo, no geral, sentimentos de medo, angústia e baixa autoestima, pois remete a retirada do símbolo da feminilidade, a mama.

Deve ser levado em consideração os anseios da paciente no futuro, avaliando inclusive se a paciente pretende amamentar os seus filhos em uma futura gestação, já que, com a retirada das mamas isso não será possível. O enfermeiro deve 
estar sempre atento para acolher e orientar a paciente em suas decisões, a fim de prestar uma assistência resolutiva e humanizada especialmente quando se está tratando de pacientes historicamente fragilizadas por concepções equivocadas sobre o processo fisiopatológico do câncer de mama.

O tema proposto foi essencial para o processo de ensino aprendizagem, contribuindo de maneira impar para o conhecimento sobre o câncer de mama. Portanto, espera-se que a presente pesquisa contribua para os desenvolvimentos de novos estudos, sempre voltado a melhorar a qualidade de vida da mulher.

\section{Referências}

Amendola, L. C. B. (2005). Vieira, R. A contribuição dos genes BRCA na predisposição hereditária ao câncer de mama. Revista Brasileira de Cancerologia; 51(4), 325-330

Barata, R. B. (2009). Como e porque as desigualdades sociais fazem mal à saúde. Fiocruz.

Brasil. Ministério da Saúde. Secretaria de Atenção à Saúde. (2013). Departamento de Atenção Básica. Controle dos cânceres do colo do útero e da mama I Ministério da Saúde, Secretaria de Atenção à Saúde, Departamento de Atenção Básica. (2a ed.), Editora do Ministério da Saúde.

D’ávila, K., Vargas, L., Machado, L., Sousa, L., Saffer, P., Alexandre, C., Castro, E. C., (2000). Câncer de Mama, Fundação Faculdade Federal de Ciências Médicas de Porto Alegre, Departamento de Genética e Evolução, Disciplina de Genética Porto Alegre.

Figueiredo, N. M. A., Moreira, M. C., Machado, Wiliam, C. A., Santos, I., Camargo, T. C., Braune, M. (2010). O Corpo Sadio que adoece por câncer: um “caranguejo" no corpo in Viana, D. L., Leão, E. R., \& Figueiredo, N., M. A., (Organizadores) -Yendis Editora.

Gomes, R., Skaba, M. M. V. F., Vieira, R. J. S. (2002). Reinventando a vida: proposta para uma abordagem sócio-antropológica do câncer de mama feminina. Cad Saúde Pública;18(1),197-204.

Inca. Instituto Nacional De Câncer. (2011). Coordenação Geral de Ações Estratégicas. Coordenação de Prevenção e Vigilância. Estimativa 2012: incidência de câncer no Brasil, Inca. 118.

Leite, F. M. C., Bubach, S., Amorim, M. H. C., Castro, D. S., \& Primo, C. C. (2012). Mulheres com Diagnóstico de Câncer de Mama em Tratamento com Tamoxifeno: Perfil Sociodemográfico e Clínico. Revista Brasileira de Cancerologia. 57(1), 15-21.

Machado, M. X., Soares, D. A. S., \& Oliveira, S. B. (2017). Significados do câncer de mama para mulheres no contexto do tratamento quimioterápico. Physis Revista de Saúde Coletiva, Rio de Janeiro, 27(3), 433-451.

Monteiro, A. (2011). O dilema da decisão de Mastectomia Bilateral como prevenção lógicas do Câncer de Mama: aspectos éticos e bioéticos. Revista - Centro Universitário São Camilo -;5(4), 443-450.

Robbins, V., \& Cotran, K. (2010). Bases patológicas das doenças/ Vinay Kumar [et al]; tradução de Patrícia dias Fernandes [et al]. Rio de janeiro: Elsevier.

Sant'anna, D. B. (2001). Corpos de passagem: ensaios sobre a subjetividade contemporânea. Estação Liberdade.

Silva, A. G. (2010). A parteira de Monte Azul. JM Gráfica e Editora Ltda,

Silva, S. É. D., et al. (2010). Representações sociais de mulheres mastectomizadas e suas implicações para o autocuidado. Rev. bras. Enferm. Brasília, 63(5), 727-734.

Silver, L. M. (2001). De volta ao éden. Tradução Dinah de Abreu Azevedo. Mercuryo.

Vieira, C. P., Lopes, M. H. B. M., Shimo, A. K. (2007). Sentimentos e experiências na vida das mulheres com câncer de mama. RevEscEnferm USP; 41(2), 311-6. 